\section{Recursos humanos e trabalho em saúde: os desafios de uma agenda de pesquisa}

\author{
Human resources and health work: challenges \\ for a research agenda
}

\author{
1 Faculdade de Medicina, \\ Universidade Federal de \\ Minas Gerais, Belo Horizonte, \\ Brasil. \\ 2 Secretaria de Gestão do \\ Trabalho e da Educação em \\ Saúde, Ministério da Saúde, \\ Brasília, Brasil. \\ Correspondência \\ A. A. Assunção \\ Programa de Pós-graduação \\ em Saúde Pública, Faculdade \\ de Medicina, Universidade \\ Federal de Minas Gerais. \\ Av. Alfredo Balena 190, sala \\ 8009, Belo Horizonte, $M G$ \\ 30130-100, Brasil. \\ adavila@medicina.ufmg.br
}

\begin{abstract}
This article discusses several key concepts for human resources policy in health in the context of Latin America's regional integration efforts. The article focuses on different concepts of integration to emphasize the analytical distinction between regional and conceptual integration. It also presents labor and human resources concepts before discussing, in the final analysis, the challenges that a common research agenda faces in the context of current health sector reforms in Latin America. The conclusion emphasizes the need to develop a technology and research system capable of supporting the agenda for exchange between MERCOSUR member countries.
\end{abstract}

Human Resources; Work; Concept Formation
Ada Ávila Assunção 1 Soraya Almeida Belisário 1 Francisco Eduardo Campos 1,2 Luciana Souza D'Ávila 1

\section{Contextualizando o tema}

Nas últimas décadas, iniciativas importantes buscam a integração dos países da América Latina, ou seja, de suas fronteiras, visando a obter força para o desenvolvimento almejado e para a estabilização econômica, não somente favorecendo a livre circulação de bens e produtos, mas incentivando e propiciando meios para a circulação de pessoas ${ }^{1}$.

No Tratado de Assunção (assinado em 31 de março de 1991), numa Carta Constitutiva que cria o Mercado Comum do Sul (MERCOSUL), tem-se que a ampliação das atuais dimensões de seus mercados nacionais, através da integração, constitui condição fundamental para acelerar seus processos de desenvolvimento econômico com justiça social. Torna-se explícito o objetivo de melhorar as condições de vida dos habitantes da região, por meio do desenvolvimento científico e tecnológico dos Estados Membros e da modernização de suas economias para ampliar a oferta e a qualidade dos bens de serviços disponíveis.

A integração regional propiciada pelo MERCOSUL favorece a implementação de ações no setor saúde, entre outros. O Subgrupo de Trabalho 11 Saúde, parte do Grupo Mercado Comum que integra o atual organograma do MERCOSUL, busca definir e desencadear ações vinculadas à melhoria da qualidade e segurança dos produtos e serviços ofertados à população, 
à adequação dos sistemas de controle sanitário e à elaboração de propostas de procedimentos de organização, de sistematização e difusão da informação referente à área da saúde entre os Estados Membros.

A integração estimula o aprimoramento dos sistemas de saúde, por exemplo, impulsiona a integração dos sistemas estruturais nacionais de atenção à saúde das populações. Mas é preciso levar em conta os desequilíbrios que a integração em marcha poderá trazer, como a disseminação de vetores patógenos na medida em que facilita a circulação de produtos e pessoas 2 . O movimento de integração enfrenta o desafio de superar as assimetrias sócio-econômicas existentes entre os países, para as quais os problemas de saúde das suas populações constituem-se indicadores das desigualdades sociais geradas em contextos específicos.

Sobre a importância do processo de integração regional dos países do MERCOSUL, Gallo et al. 2 sustentam a relevância do setor para a realização de políticas sociais. Considera-se a saúde fundamental para os objetivos de desenvolvimento pretendidos. Em 1990, a Conferência Sanitária Pan-Americana já destacava a saúde no processo de desenvolvimento, explicitando duas razões: (1) a estreita interdependência entre saúde e desenvolvimento humano; (2) a contribuição que o setor pode levar ao progresso social dos povos na região ${ }^{3}$.

Quanto à temática saúde e desenvolvimento, Paim ${ }^{4}$ lembra um número significativo de estudos publicados cujos resultados enfatizam as relações entre os níveis de saúde e os fatores socioeconômicos determinantes das condições materiais de existência de grupos humanos de uma dada sociedade. Não é demais lembrar o surgimento de investigações sistemáticas sobre o tema condições de vida e saúde desde os séculos XVIII e XIX, com o aparecimento da medicina social. Diferentes abordagens conceituais no século XX prosseguem o estudo da causalidade em saúde cada vez mais forte em sua hipótese da determinação social do processo saúde-doença.

Ressalta-se que o conteúdo relacionado aos problemas de saúde está presente não apenas nos planos do MERCOSUL, ele encontra-se contemplado nos três objetivos que compõem o conjunto de oito objetivos elaborados, em 2000, por 189 países das Nações Unidas reunidos na Cúpula do Milênio, cuja expressão política está refletida na Declaração do Milênio 5 (p. XIII), marco do esforço conjunto para "revitalizar a cooperação internacional destinada aos países menos desenvolvidos e, em especial, a combater decisivamente a pobreza extrema". Por essa razão, são vários os objetivos de desenvolvimento do milênio relacionados diretamente à melhoria da saúde da população em geral e que dizem respeito aos aspectos sanitários específicos, como enfermidades de notificação compulsória, acesso a medicamentos, saúde reprodutiva e água potável. Para as Nações Unidas 5 (p. 142), “a boa saúde é um fator decisivo para o bem-estar das pessoas, famílias, comunidades e, por sua vez, um requisito de desenvolvimento humano com eqüidade".

Adquirem importância no cenário da integração regional os recursos humanos em saúde, atores fundamentais para a realização das metas de saúde e para a identificação dos desequilíbrios citados. Na atualidade têm-se discutido os efeitos das reformas no setor e as transformações surgidas no desenvolvimento dos processos produtivos sobre o campo dos recursos humanos: exigências de novas habilidades dado o incremento tecnológico, implicações imediatas das metas de saúde sobre os métodos de gestão do trabalho, mutações no emprego em tempos de globalização e reestruturação produtiva etc.

Nessa direção, atores nacionais e internacionais, do setor saúde, de outros setores relevantes e da sociedade civil, têm buscado construir coletivamente políticas e intervenções para o desenvolvimento dos recursos humanos em saúde. A Organização Mundial da Saúde (OMS) e a Organização Pan-Americana da Saúde (OPAS) dedicam o ano de 2006 aos recursos humanos em saúde. Ações concretas marcaram o Dia Mundial da Saúde e a Semana Pan-Americana da Saúde, quando foi realizado um conjunto de eventos que propiciaram divulgar e promover a valorização dos recursos humanos que atuam em saúde.

A coincidência do centro do tema Recursos Humanos em Saúde nas agendas nacional, regional e global marca a iniciativa de uma década de investimentos sustentados visando a construir uma infra-estrutura humana para os sistemas de saúde.

Emergem no cenário as preocupações relativas às novas formas de gestão do trabalho, a partir dos anos 1990, fundadas no incentivo à produtividade e qualidade ${ }^{6}$, cujos efeitos sobre a atividade concreta de trabalhadores inseridos em situações particulares e específicas ainda não foram bem dimensionados.

Como seria esperado, o setor saúde não está isento dos efeitos negativos do crescimento global e do desemprego estrutural nas sociedades industrializadas. Como favorecer a integração dos países e diminuir a desigualdade econômica em um mundo globalizado que vive crises estruturais no padrão de emprego? Lembrando Frigotto 7 (p. 42), “a globalização permite uma verdadeira vingança do capital contra o trabalho" ao contar com uma base tecnológica que permite 
um rápido deslocamento de investimentos produtivos de uma parte para outra do mundo, a fim de atingir as taxas de lucro desejadas. Assiste-se, nessa dinâmica do avanço da base material da produção capitalista, ao aumento exponencial do capital morto e à conseqüente diminuição de capital vivo, força de trabalho. O autor prossegue criticando o que ele denomina de idéia-força dominante segundo a qual não haveria outra alternativa a não ser a de "ajustar-se aos novos tempos, ingressar no processo de globalização e, para tanto, fazer o ajuste doloroso e necessário" 7 (p. 43). A citada idéia-força orienta uma lógica de desenvolvimento marcadamente desigual e destrutiva.

Desde a Cúpula das Américas, realizada em Quebec em 2001, os representantes dos Estados e os Governos de todos os países têm reconhecido que o trabalho é a melhor via para vincular a crescimento econômico e qualidade de vida dos cidadãos 8 . Sob essa perspectiva, impulsionada pelo apoio dos ministros do trabalho de 34 países membros da Organização dos Estados Americanos (OEA), a OPAS incorporou o tema da saúde dos trabalhadores no marco do Trabalho Decente da Organização Internacional do Trabalho (OIT http://www.ilo.org/punlic/spanish/decent.htm, acessado em 13/Nov/2006) e da iniciativa de Ambientes de Trabalho Saudáveis da OMS/OPAS 9, com ênfase em ações pró-ativas tendo como populações alvo, a saber: imigrantes, menores trabalhadores, mulheres trabalhadoras, pessoas com deficiências físicas, trabalhadores de terceira idade, índios, pessoas com HIV/AIDS.

Na mesma direção, o Ministério da Saúde do Brasil 10 consagra 2006 como o Ano dos Trabalhadores em Saúde. Juntamente com a representação OPAS/OMS, elabora-se uma proposta a ser desenvolvida, a qual adota como tema Gente que Faz Saúde, sinalizando a necessidade de ampliação das ações em prol dos trabalhadores em saúde no país, como se verá.

O objeto saúde no âmbito do MERCOSUL abre ou fortalece vias para a construção de uma lógica supranacional menos dura ao fundar-se nos princípios da eqüidade e universalidade da atenção à saúde. Quais elementos teórico-metodológicos subsidiariam o debate visando a obter elementos para superar as assimetrias no tocante à saúde das populações entre os Estados Membros? Estaria justificada uma estratégia de pesquisa visando a elaborar esses elementos?

Para abordar essas questões este artigo está dividido em três partes. Na primeira, são apresentados os conceitos de integração e a relevância do setor saúde para o alcance dos objetivos do MERCOSUL. Na segunda parte, contextualizando-se os serviços de saúde em período de reformas setoriais, aborda-se a discussão atual que originou uma tensão interna ao campo dos recursos humanos em saúde, a qual levou os gestores e formuladores de políticas a adotarem o termo trabalhadores da saúde em substituição ao clássico recursos humanos em saúde. Em seguida, apresentam-se os desafios epistemológicos colocados pela ciência pós-moderna. Finalmente, no artigo apresentam-se alguns elementos para uma agenda de pesquisa no campo recursos humanos em saúde, tendo como perspectiva introduzir a integração conceitual e disciplinar no quadro das necessidades de integração regional na América Latina.

\section{As demandas de integração}

Integração é o ato de integrar, tornar inteiro, completar 11. A noção tem como sinônimos as palavras conexão, coerência, nexo, relação. Quando a noção é utilizada para o âmbito físico ou geográfico, no caso, regional, ela diz respeito à quebra de fronteiras e ao aprimoramento de conexões físicas. Pode, ainda, identificar o espaço alfandegário, ou seja, da livre circulação.

Observam-se iniciativas para integração dos sistemas de saúde entre os países membros, tais como a proposta do SIS-MERCOSUL (Sistema Integrado de Saúde do MERCOSUL), que sugere a união das medidas de saúde - promoção, prevenção, recuperação e reabilitação - inseridas nos princípios da eqüidade, universalidade de atenção, participação, eficiência, integração e a descentralização 12 .

No processo de integração do complexo de saúde, espera-se a participação dos segmentos industrial, comercial, serviços, formativo e pesquisa e desenvolvimento ${ }^{2}$. Nessa perspectiva, haverá geração de empregos, o que exigirá do segmento formativo a capacidade em introduzir novas bases no mercado de trabalho, as quais são dependentes da articulação com unidades de produção, demandas epidemiológicas e centros de educação profissional.

Se tal articulação fracassar ou se não for amparada por políticas e investimentos suficientes, a livre circulação de mão-de-obra entre os países poderá gerar um impacto desfavorável no mercado de trabalho. A lei da oferta conduzirá o fluxo dos profissionais e também usuários, podendo gerar desigualdades entre as regiões metropolitanas e rurais na distribuição das profissões, principalmente em áreas fronteiriças 3 .

Reconhecendo o risco, a Declaração Sóciolaboral do MERCOSUL (assinada em 10 de dezembro de 1998) dá inicio à formalização do processo de integração regional, com a tentativa de 
adequação dos direitos trabalhistas individuais e coletivos, embasados na livre circulação de mãode-obra.

Vale ressaltar que, se por um lado, o Tratado de Assunção permitiu uma nova liberdade de escolha para os profissionais de saúde, por outro, são possíveis os efeitos indesejados. As novas formas de regulação implementadas pelas políticas de Estado em vários países convivem com a competição no mercado e a sofisticação tecnológica, a qual incentiva e foi incentivada pela acumulação do capital no setor 7 , por exemplo, produção e absorção de insumos, medicamentos, técnicas de diagnóstico etc.

A facilidade para a circulação e a tendência em tornar as matrizes curriculares cada vez mais homogêneas permitem a mobilidade de profissionais interpaíses, atraídos pela densidade tecnológica e disponibilidade de recursos nos serviços.

Numa pesquisa recente, o desejo por maior acesso à tecnologia, equipamentos e recursos para a prática médica apareceu nas respostas de $75 \%$ de uma amostra de médicos imigrantes. Nota-se que Assembléias Mundiais de Saúde de 2002 e 2004 já demonstraram interesse em apreciar os efeitos negativos da migração de médicos sobre o sistema saúde de países em desenvolvimento, dada a hipótese de que as populações mais carentes coincidem com as populações com menos acesso às práticas atualizadas de atenção à saúde e que seriam justamente as populações que estariam deixando de fixar os seus médicos. Para se ter uma idéia, segundo a Associação Médica Americana, no Canadá 23\% dos médicos atuantes foram treinados em outro país; nos Estados Unidos a taxa é semelhante (23,5\%) 13.

Os estudos sobre mercado de trabalho em saúde trazem elementos para o desenvolvimento de novos esquemas de organização dos serviços. O conhecimento da realidade do emprego e dos novos modelos de gestão do trabalho impulsionaram políticas de formação e de educação continuada, uma vez identificada a defasagem de competências e habilidades entre a formação pregressa e a implantação dos novos sistemas. A título de exemplo, uma pesquisa em andamento coloca em evidência as dificuldades dos agentes de saúde em dispensar os medicamentos em uma Unidade Básica de Saúde após a implantação do sistema informatizado de controle de estoque 14 .

A integração regional do trabalho também apresenta entraves relacionados à grande diferença das modalidades de organização dos sistemas de saúde e da formação de recursos humanos entre os Estados Membros do MERCOSUL. Existe uma heterogeneidade do papel dos Estados na regulamentação da formação 3,15,16. Nor- matização dos conceitos, currículos e exercício das profissões, além de corrigir as disparidades, favoreceria o elo entre o ensino e os serviços 5 . No Brasil, por exemplo, houve um aumento expressivo do número de cursos na área da saúde nos últimos anos e, assim como nos outros países do bloco, a enfermagem aparece como a categoria profissional crítica. Existem inúmeras definições para enfermeiro, técnico ou auxiliar, o que dificulta o ajuste dos desequilíbrios de oferta, demanda, empregos e salários e também a contratação de profissionais estrangeiros 3,15,17.

Considerando-se o cotidiano do trabalho em saúde, junto a um sistema demonitorização devariáveis de oferta, demanda e desempenho profissional, nos moldes propostos por Campos et al. 15, não seria excessivo pensar em gerar políticas capazes de propiciar meios para diagnosticar as condições de realização das tarefas preconizadas e projetar modelos pedagógicos de formação dos diversos profissionais voltados para as competências requeridas pelos sistemas, atentando-se dos riscos da formação voltada exclusivamente para operação dos sistemas. O desafio convoca as reflexões amadurecidas pelos especialistas em educação na América Latina. A esse propósito, vale lembrar Gentili 18 e sua tese sobre a desintegração da promessa da escola como entidade integradora. Para o autor, passou-se de uma lógica de integração em função das necessidades e demandas de caráter coletivo, a uma lógica, nos seus dizeres, "estritamente privada e guiada pela ênfase nas capacidades e competências que cada pessoa deve adquirir no mercado educacional para atingir uma melhor posição no mercado de trabalho" 18 (p. 81).

Além de evitar abordagens muito centradas no mercado e planos de formação instrumentalistas, o movimento de integração ganharia em força ao superar as dificuldades em discutir alternativas para o enfrentamento das situações imediatas e vivenciadas nos serviços. No entanto, são abundantes as análises mais globais. Sem negar a necessidade do nível de análise mais global, sempre proveitosa, o caráter genérico, embora correto, das análises das políticas de saúde e das políticas de formação de recursos humanos em saúde, enfrenta os seus limites quando o objetivo é discutir alternativas para as situações imediatas precárias.

O movimento se beneficiaria de uma discussão mais ampla das dimensões pedagógicas das relações sociais contemporâneas e do papel da educação para a cidadania, que naturalmente não se esgota na educação estritamente vinculada ao trabalho produtivo. Kuenzer 19 enfatiza a contribuição de propostas pedagógicas mais orgânicas com os interesses dos trabalhadores. 


\section{Recursos humanos e trabalhadores da saúde: conceitos e evolução}

A noção de recursos humanos já propalada neste artigo refere-se a algo passível de administração, sendo utilizado, como lembram Medeiros \& Rocha 20 (p. 400), “com o propósito explícito de intervir numa situação para produzir e aprimorar, ou ainda, para administrar esse recurso específico, que é a capacidade de trabalho das pessoas". Posições racionalistas e baseadas em premissas normativas do planejamento e do poder estão presentes no campo dos recursos humanos e conferem uma concepção instrumentalizada e coisificada do trabalho humano 20 .

A escola dos recursos humanos em saúde vivencia tensões em sua estrutura clássica, ao ser impulsionada pelos desafios oriundos das flexibilizações e deterioração nas relações de trabalho. Evoluções no sistema, mutações no trabalho e nas profissões, regras de funcionamento e políticas sociais buscando a eqüidade são elementos indispensáveis para uma análise da tensão vivenciada pela escola dos recursos humanos.

À luz das críticas teóricas mencionadas e dos ganhos do movimento social dos trabalhadores, a expressão recursos humanos assumiu ressignificado nas últimas décadas do século $\mathrm{XX}$, incorporando, de certa forma, o sentido dado ao termo força de trabalho pela economia política, ao fazer uso descritivo e analítico dos fenômenos do mercado de trabalho, como: emprego, desemprego, renda, assalariamento 21 .

$\mathrm{O}$ engajamento afetivo dos operadores no desempenho de suas tarefas explica o número crescente de estudos e de modelos de investigação voltados para a compreensão da subjetividade no trabalho. Para Dussault 22, as organizações de saúde são organizações profissionais por causa de sua dependência em relação ao trabalho de seus integrantes, sua formação e seu empenho. Apesar da ausência das condições ideais e ao dar conta das demandas complexas, inusitadas e não previstas, os trabalhadores da saúde reafirmam a sua identidade, desenvolvem as suas habilidades 23,24. Nem recurso humano, nem força de trabalho. Sujeitos que buscam sentido no trabalho, trabalhadores!

Está descrito o caráter subjetivo e intersubjetivo do cuidado em saúde, deslocando a idéia de cuidado como um conjunto de procedimentos tecnicamente orientados para o bom êxito de certo tratamento 25 . Nos estabelecimentos de saúde, as exigências são contraditórias, mas os trabalhadores constroem uma prática para contorná-las, que só é eficaz porque é rica em conhecimentos. São os conhecimentos que permitem responder aos imprevistos no desenvolvimento, implantação e manutenção dos sistemas 26. Torna-se frágil a abordagem que reduz os recursos humanos em saúde ao status conferido aos recursos materiais ou medidas terapêuticas, para dar lugar ao sentido que as atitudes práticas assumem nas diversas situações em que se reclama uma situação terapêutica.

Ao explicitar a distinção entre recursos humanos e recursos materiais, surge a pertinência do uso da noção trabalho. Recentemente, a escola de recursos humanos em saúde no Brasil operou uma transformação em sua estrutura, que procura envolver trabalho, trabalhador e sociedade nos termos da sociologia do trabalho em sua linha gestão do trabalho. No entanto, restam a superar as carências teórico-metodológicas que se apresentam no bojo de mudanças operadas no plano prático.

Os limites da escola de Recursos Humanos em superar os desafios postos na implantação de sistemas de saúde sob os princípios da universalidade e da eqüidade, e as conquistas dos trabalhadores impulsionaram as políticas do Ministério da Saúde do Brasil que dão positividade à construção de um novo modelo para a área de recursos humanos e que permitem aos grandes projetos adequar as condições de emprego e as condições de trabalho ao papel e à função social a serem exercidos pelo trabalhador da saúde. Notar a criação da Mesa Nacional de Negociação Permanente do SUS como estratégia de tratamento dos conflitos, a fim de garantir a negociação e a pactuação entre os diversos atores que atuam no sistema 27.

O Ministério da Saúde do Brasil afirma que o setor saúde é um trabalho-intensivo. Em seu documento recente, Desprecarização do Trabalho no SUS. Perguntas e Respostas, assume que o setor não é concentrado; ao contrário, está distribuído em inúmeros locais, o que reduz consideravelmente as chances do controle das condições do seu exercício 28 , mas não impede estratégias a curto e a médio prazo. Para reverter, por exemplo, o quadro de ausência de direitos e benefícios trabalhistas que, na área da saúde, ocasionaria um alto grau de desmotivação e, conseqüentemente, grande rotatividade desses trabalhadores nos serviços, prejudicando a continuidade das políticas e programas de atenção à saúde da população, o Ministério da Saúde adotou a estratégia de implementação de uma política de valorização do trabalhador, considerada passo fundamental para promover a desprecarização e a consolidação do SUS 28 .

A 3ạ Conferência de Gestão do Trabalho e da Educação em Saúde, fórum da manifestação do controle social sobre as políticas públicas de saúde, realizada no período de 27 a 30 de 
março de 2006, obteve grande adesão dos Estados e municípios. Com o tema Trabalhadores de Saúde e a Saúde de Todos os Brasileiros: Práticas de Trabalho, de Gestão, de Formação e de Participação, o encontro reuniu cerca de 1.500 delegados de todo o país para discutir gestão do trabalho; educação na saúde; participação do trabalhador; financiamento; controle social e produção e incorporação de saberes a partir das práticas de trabalho, de gestão, de formação e de participação, com foco no cuidado e na saúde do trabalhador do SUS. Viram-se assim os temas trabalho e os trabalhadores do SUS na agenda política com desdobramentos práticos e imediatos 29.

Sobre as condições de trabalho, os relatórios das centenas de conferências locais sinalizam os enfrentamentos cotidianos dos trabalhadores diante das condições inadequadas de trabalho. Evidencia-se a necessidade de iniciativa institucional, procurando conhecer o panorama dos fatores técnico-organizacionais, do ambiente e da segurança no trabalho nos estabelecimentos de saúde.

No âmbito latino-americano, em janeiro de 2006, realizou-se uma Oficina Latino-Americana em Ouro Preto, em que os relatos sobre as condições de trabalho e saúde dos trabalhadores do setor da saúde mostram que a atenção à saúde dos trabalhadores do setor, à semelhança do que ocorre para o conjunto dos trabalhadores, é bastante deficiente ${ }^{30}$. A tradicional abordagem relação custo-benefício em busca da eficiência no setor saúde foi contestada pelos especialistas presentes.

Os estudos científicos também esclarecem sobre inadequação das condições materiais e organizacionais do trabalho nos estabelecimentos de saúde. Os constrangimentos vivenciados pelos sujeitos estão associados às condições de trabalho, as quais foram identificadas como fatores de risco para a insatisfação no trabalho $31,32,33,34$. Os autores afirmam que a insatisfação pode interferir na qualidade do trabalho realizado, assim como produzir efeitos negativos sobre a saúde dos trabalhadores da saúde 35,36,37. Mais da metade dos incidentes ocorridos no trabalho, no Reino Unido, por exemplo, foi associada ao cansaço, e $28 \%$ à pressão no trabalho. A depressão influenciou negativamente no cuidado prestado 34 . Os autores chamam atenção para a necessidade de diminuir as horas trabalhadas e a privação do sono, para que os médicos possam prestar um cuidado de qualidade.

\section{A integração disciplinar}

Até aqui foi dito sobre os tempos de mobilidade espaço-temporal, a convivência de profissionais formados por diferentes matrizes curriculares e sob diferenciadas regulamentações corporativas nos estabelecimentos de saúde dos Estados Membros. Abordar o trabalho, os processos, as competências, a subjetividade... exigirá um outro tipo de mobilidade, interdisciplinaridade, que será tratada a seguir.

Pesquisa e desenvolvimento é um dos cinco segmentos que formam o complexo de saúde. Além da participação do segmento formativo e educacional no processo de integração, a inclusão do componente de pesquisa e desenvolvimento mostra-se vantajosa, já que agrega a perspectiva de integração conceitual. Essa vertente de integração implica uma integração metodológica e disciplinar, associada à cooperação e à coordenação entre os setores: recursos humanos e trabalho em saúde. A título de exemplo, cita-se a desejada articulação dos centros de educação profissional para responder às demandas epidemiológicas, como se viu no caso das ações de controle do dengue 39 , a qual também está presente nas preocupações atuais com o problema de alimentos ou na recente epidemia do cólera. Em ambas as situações, coloca-se em especial destaque os médicos veterinários, os nutricionistas e os engenheiros sanitários ${ }^{13}$. Como estabelecer uma agenda de pesquisa visando à construção de indicadores com a participação integrada das profissões citadas e que, num passado recente, estiveram isoladas e, muitas vezes, ausentes dos estabelecimentos de saúde?

Acatando a proposição de Nicolescu 40, físico preocupado com a necessidade moderna da transdisciplinaridade, os conhecimentos e os saberes que uma civilização não pára de acumular poderiam ser integrados no interior daqueles que compõem essa civilização. Vale lembrar que, na ciência moderna, o conhecimento avança pela especialização, sendo tanto mais rigoroso quanto mais restrito torna-se o seu objeto. Nesse plano reside, no entender de Santos 41 (p. 46), "o que hoje se reconhece ser o dilema básico da ciência moderna: o seu rigor aumenta na proporção direta da arbitrariedade com que espartilha o real. Sendo um conhecimento disciplinar, tende a ser um conhecimento disciplinado, isto é, segrega uma organização do saber orientada para policiar as fronteiras entre as disciplinas e reprimir os que as quiserem transpor".

Em momento de ruptura das fronteiras geográficas, como desenvolver um plano para romper as fronteiras disciplinares? No caso do setor saúde, a elaboração de políticas públicas calca- 
das em diagnósticos das realidades sanitárias e nas necessidades dos serviços e de seus atores dependerá da capacidade dos profissionais das áreas em apropriar-se de ferramentas de diferentes planos disciplinares que permitam abordagens mais complexas que, por isso mesmo, possam melhor responder às exigências da realidade imediata, como exposto anteriormente.

Para a agenda de pesquisa no campo dos recursos humanos em saúde, em um primeiro tempo, seriam esperados elementos científicos para a construção dos indicadores e bases de dados e sistemas de seguimento e avaliação sobre mercado e condições de trabalho em saúde na região. No entanto, o desafio é complexo. A sensibilidade dos tomadores de decisão e a disponibilidade dos pesquisadores em transitar em áreas conexas serão fundamentais para o enfrentamento posto.

Os atributos de universalidade e de eqüidade colocam desafios para a organização dos sistemas, pois na porta de entrada os serviços nem sempre estão preparados para responder ao usuário em sua necessidade sentida. A confluência entre a medicina, a sociologia, a economia, a saúde pública, entre outras, seria vital para compreender a racionalidade do usuário 25.

A tentativa de se desenvolver uma abordagem interdisciplinar para estudar um assunto de significativa relevância social sempre esteve presente na história da ciência ocidental, sobretudo no que se refere à busca de compreensão de fenômenos sociais que atingem grandes contingentes populacionais. Emergem, na metade do século XX, investimentos científicos calcados na pluridisciplinaridade e interdisciplinaridade. A primeira diz respeito ao estudo de um objeto de uma mesma e única disciplina por várias disciplinas ao mesmo tempo. Nicolescu 40 esclarece que o objeto será enriquecido pelo cruzamento de várias disciplinas, na medida em que o objeto é aprofundado por uma fecunda contribuição pluridisciplinar. No caso da interdisciplinaridade, ocorre transferência de métodos de uma disciplina para outra.

A transdisciplinaridade diz respeito àquilo que está ao mesmo tempo entre as disciplinas, através das disciplinas e além de qualquer disciplina. Para Nicolescu 40, o objetivo da transdisciplinaridade é a compreensão do mundo presente, para o qual um dos imperativos é a unidade do conhecimento.

\section{Considerações finais}

Viu-se que as mudanças de paradigma e a evidência dos efeitos das exigências de formação para o controle e implantação dos sistemas que estão evoluindo geram perguntas nem sempre suficientemente elaboradas, ou demandas por investigações capazes de elucidar os fenômenos do emprego, do trabalho e da educação.

Simultaneamente aos tempos de integração regional, ou, provocados por eles, novos objetos são definidos e provocam categorias de análise mais apropriadas às realidades postas, como é o caso do trabalho em saúde. Tratar da subjetividade do trabalho tendo como único referencial a noção de recursos humanos seria inapropriado, pois as reações humanas frente aos desafios postos pela organização do processo de trabalho em saúde convoca a reformulação dos conhecimentos e o entrelaçamento de saberes diferenciados e abordagens menos superficiais dos problemas de qualidade na atenção à saúde das populações. Serão profícuas as perspectivas teóricas construídas no processo.

À luz das demandas apresentadas e inscritas nas agendas institucionais nos âmbitos nacional e internacional e da pertinência da elaboração de argumentos sofisticados para gerar medidas visando à melhoria da realidade sanitária das coletividades, vislumbra-se propor um modelo de investigação e elaborar subsídios práticos. Nessa direção, está convocado um debate sobre a abordagem interdisciplinar ou, quem sabe, transdisciplinar, na agenda dos recursos humanos em saúde.

Para a integração disciplinar surgem os entraves mencionados, os quais se traduzem em desafios para a pesquisa. Está em curso a oportunidade de definição de indicadores universais que representem a realidade de cada país a fim de superar a carência de informações no campo. Além disso, para superar os desafios será necessária uma conexão entre essas informações que podem trazer subsídios para o conhecimento da situação de trabalho na esfera da saúde.

A pesquisa se constituirá em força material à medida que conseguir apreender as determinações de longo prazo e, portanto, de natureza estrutural das relações socioeconômicas e de suas expressões nas condições de vida das populações dos Estados Membros do MERCOSUL, e nos processos saúde-doença e suas imbricações no desenvolvimento das políticas públicas de saúde. 


\section{Resumo}

Neste artigo são apresentados elementos conceituais considerados chave para as politicas dirigidas aos recursos humanos em saúde no contexto latino-americano. Foram focalizados os conceitos de integração, enfatizando-se os temas integração regional e integração conceitual. São apresentados os conceitos sobre recursos humanos e trabalho, para, ao final, serem debatidos os desafios postos diante do objeto de pesquisa compartilhado, tendo como cenário o contexto das reformas setoriais em curso na América Latina. Concluindo, afirma-se a necessidade, já debatida pelos autores, de se desenvolver um sistema de pesquisa e de tecnologia capaz de sustentar a agenda de intercâmbio entre os países membros do MERCOSUL.

Recursos Humanos; Trabalho; Formação de Conceito

\section{Referências}

1. Loguercio JE. A livre circulação de trabalhadores no MERCOSUL e o impacto jurídico nas relações de trabalho. Montevidéu: Friedrich Ebert Stiftung; 2003. (Serie Documentos sobre el MERCOSUR).

2. Gallo E, Claret A, Costa L, Nunes N. Cooperação em saúde e integração regional: políticas para promover a dinamização do complexo da saúde no MERCOSUL. In: Gallo E, Costa L, organizadores. SIS-MERCOSUL: uma agenda para a integração. Brasília: Organização Pan-Americana da Saúde/ Ministério da Saúde; 2004. p. 21-31. (Série Técnica: Projeto de Desenvolvimento de Sistemas e Serviços de Saúde, 9).

3. Rodríguez RH. MERCOSUL: um processo de integração. In: Organização Pan-Americana da Saúde, organizador. Recursos humanos em saúde no MERCOSUL. Rio de Janeiro: Organização PanAmericana da Saúde; 1995. p. 9-29.

4. Paim JS. Abordagens teórico-conceituais em estudos de condições de vida e saúde: notas para reflexão e ação. In: Barata RB, organizador. Condições de vida e saúde. Rio de Janeiro: ABRASCO; 1997. p. 7-30.

5. Naciones Unidas. Objetivos de desarrollo del milenio. Una mirada desde América latina y el Caribe. Santiago del Chile: Naciones Unidas; 2005.

6. Coordenação Geral de Desenvolvimento de Recursos Humanos para o SUS, Secretaria de Projetos Especiais de Saúde. Agenda de prioridades para a política de recursos humanos na gestão do SUS. Brasília: Ministério da Saúde; 1997.

7. Frigotto G. Educação, crise do trabalho assalariado e do desenvolvimento: teorias em conflito. In: Frigotto G, organizador. Educação e crise do trabalho: perspectivas de final de século. Petrópolis: Editora Vozes; 2002. p. 25-54.

\section{Colaboradores}

Todos os autores participaram da elaboração da estrutura do artigo e da revisão da literatura.
8. Organización Panamericana de la Salud. Informe sobre la salud y la seguridad en el trabajo en la región de las Américas: alianza estratégica entre los ministros de trabajo y de salud. Bogotá: Organización Panamericana de la Salud; 2004.

9. Organización Panamericana de la Salud. Representación de Colombia. Informe sobre la salud y la seguridad en el trabajo en la región de las Américas: alianza estratégica entre los ministros de trabajo y de salud. Bogotá: Organización Panamericana de la Salud; 2004.

10. Ministério da Saúde. Gestão do trabalho e da regulação profissional em saúde. Brasília: Ministério da Saúde; 2005.

11. Ferreira $\mathrm{ABH}$. Novo dicionário Aurélio da língua portuguesa. Rio de Janeiro: Editora Nova Fronteira; 1976.

12. Holanda EGM. Apresentação - o MERCOSUL e a integração. In: Gallo E, Costa L, organizadores. SIS-MERCOSUL: uma agenda para a integração. Brasília: Organização Pan-Americana da Saúde/ Ministério da Saúde; 2004. p. 19. (Série Técnica: Projeto de Desenvolvimento de Sistemas e Serviços de Saúde, 9).

13. Avraham A, Akhtar T, Matallana MA, Muthuswamy V, Olowu FA, Tallo V, et al. Physician migration: views from professionals in Colombia, Nigeria, India, Pakistan and the Philippines. Soc Sci Med 2005; 61:2492-500.

14. Núcleo de Estudos em Saúde Coletiva. Projeto Recursos Humanos, formação e trabalho em saúde. Relatório de pesquisa. Belo Horizonte: Universidade Federal de Minas Gerais; 2006. 
15. Campos F, Brito P, Rígoli F. O campo dos recursos humanos em saúde no MERCOSUL, In: Organização Pan-Americana de Saúde, organizador. Recursos humanos em saúde no MERCOSUL. Rio de Janeiro: Organização Pan-Americana da Saúde; 1995. p. 31-46.

16. Gallo E, Costa L, Moraes A. A integração dos sistemas de saúde que atende a população fronteiriça dos países do MERCOSUL - SIS-MERCOSUL. In Gallo E, Costa L, organizadores. SIS-MERCOSUL: uma agenda para a integração. Brasília: Organização Pan-Americana da Saúde/Ministério da Saúde; 2004. p. 43-53. (Série Técnica: Projeto de Desenvolvimento de Sistemas e Serviços de Saúde, 9).

17. Alves ED, Leite CCF. Perspectivas históricas da participação da enfermagem no MERCOSUL. Rev Eletrônica Enferm 1999; 1(1). http://www.fen.ufg. $\mathrm{br} /$ revista.htm (acessado em 04/Ago/2006).

18. Gentili, P. Educar para o desemprego: a desintegração da promessa integradora. In: Frigotto G, organizador. Educação e crise do trabalho: perspectivas de final de século. Petrópolis: Editora Vozes; 2002. p. 76-99.

19. Kuenzer A Z. Desafios teórico-metodológicos da relação trabalho-educação e o papel social da escola. In: Frigotto G, organizador. Educação e crise do trabalho: perspectivas de final de século. Petrópolis: Editora Vozes; 2002. p. 55-75.

20. Medeiros SM, Rocha SMM. Considerações sobre a terceira revolução industrial e a força de trabalho em saúde em Natal. Cienc Saúde Coletiva 2004; 9:399-409.

21. Rovere M. Planificación estratégica de recursos humanos en salud. Washington DC: Organización Panamericana de la Salud; 1996.

22. Dussault J. A gestão dos serviços públicos de saúde: características e exigências. Rev Adm Pública 1992; 26:8-19.

23. Nogueira RP. A força de trabalho em saúde. In: Médici AC, Ramos-Paim E, Machado MH, Sayeg MA, Passos-Nogueira R, organizadores. Planejamento I - recursos humanos em saúde. Rio de Janeiro: Escola Nacional de Saúde Pública, Fundação Oswaldo Cruz; 1987. p. 13-23. (Textos de Apoio).

24. Guedes RM, Lima FPA, Assunção AA. O programa de qualidade no setor hospitalar e as atividades reais da enfermagem: o caso da medicação. Ciênc Saúde Coletiva 2005; 10:707-18

25. Ayres JRCM. Cuidado e reconstrução das práticas de saúde. Interface Comun Saúde Educ 2003/2004; 8:73-91.

26. Assunção AA, Luz MG. O componente afetivo na atividade da enfermagem: o caso do banco de leite humano. REME Rev Min Enferm 2001; 5:13-9.

27. Ministério da Saúde. Mesa nacional de negociação permanente. Brasília: Ministério da Saúde; 2006.

28. Ministério da Saúde. Desprecarização do trabalho no SUS. Perguntas e respostas. Brasília: Ministério da Saúde; 2006.
29. Ministério da Saúde. Diretrizes nacionais para a instituição de plano de carreiras, cargos e salários no âmbito do Sistema Único de Saúde. Brasília: Ministério da Saúde; 2006.

30. Núcleo de Estudos em Saúde Coletiva. Condições de trabalho e saúde dos trabalhadores da saúde. Relatório final. Ouro Preto: Universidade Federal de Minas Gerais; 2006.

31. Melo EMC, Assunção AA, Ferreira RA. O trabalho dos pediatras em um serviço público de urgências: fatores intervenientes no atendimento. Cad Saúde Pública; no prelo.

32. Murray A, Montgomery JE, Chang H, Rogers WH, Inui T, Safran DG. Doctor discontent: a comparison of physician satisfaction in different delivery system settings, 1986 and 1997. J Gen Intern Med 2001; 16:452-9.

33. Johnson JF, Hall EM, Ford DE, Mead LA, Levine DM, Wang NY, et al. The Psychosocial work environment of physicians: the impact of demands and resources on job dissatisfaction and psychiatric distress in a longitudinal study of Johns Hopkins Medical School Graduates. J Occup Environ Med 1995; 37:1151-9.

34. Bertram DA, Hershey CO, Opila DA, Quirin O. A measure of physician mental work load in internal medicine ambulatory care clinics. Med Care 1990; 28:458-66.

35. Nogueira-Martins AL. A saúde do médico. http:// www.portalmedico.org.br (acessado em 05/ Jul/2003).

36. Wiley JF, Fuchs S, Brotherton SE, Burke G, Cull WL, Friday J, et al. A comparison of pediatric emergency medicine and general emergency medicine physicians' practice patterns: results from the Future of Pediatric Education, II Survey of Sections Project. Pediatr Emerg Care 2002; 18:15-8.

37. Arnetz BB. Psychosocial challenges facing physicians of today. Soc Sci Med 2001; 52:203-13.

38. Firth-Cozens J, Greenhalgh J. Doctors'perceptions of the link between stress and lowered clinical care. Soc Sci Med 1997; 44:1017-22.

39. Ministério da Saúde. Plano Regional de intensificação das ações de controle da dengue no MERCOSUL. Brasília: Ministério da Saúde; 2005.

40. Nicolescu B. Um novo tipo de conhecimento - transdisciplinaridade. In: Nicolescu B, Pineau G, Maturana H, Random M, Taylor P, organizadores. Educação e transdisciplinaridade. Brasília: Organização das Nações Unidas para a Educação, a Ciência e a Cultura; 2000. p. 13-29.

41. Santos BS. Um discurso sobre as ciências. 13a Ed. Porto: Edições Afrontamento; 2002.

Recebido em 18/Jun/2006

Versão final reapresentada em 17/Jan/2007

Aprovado em 13/Fev/2007 